Research Article

\title{
The Impact of Financial Market Development on Agricultural Factor Misallocation: Household-Level Evidence from China
}

\author{
Song Liu $\left(\mathbb{D}\right.$, Xiongzhi Wang $\left(\mathbb{D}\right.$, Mengyuan Yang $\mathbb{D}^{D}$, and Ziling Wang $\mathbb{( D}$ \\ College of Economics and Management, South China Agricultural University, Guangzhou 510642, China \\ Correspondence should be addressed to Xiongzhi Wang; flyhawkren@163.com
}

Received 13 March 2021; Revised 15 April 2021; Accepted 19 April 2021; Published 26 April 2021

Academic Editor: Łukasz Jankowski

Copyright ( $) 2021$ Song Liu et al. This is an open access article distributed under the Creative Commons Attribution License, which permits unrestricted use, distribution, and reproduction in any medium, provided the original work is properly cited.

\begin{abstract}
We study the impact of financial market development on the allocation of agricultural factors in China, using national household-level survey data from 2010 to 2014. Our empirical results show the following: (1) the prices of capital and labor are negatively distorted, whereas the price of land is positively distorted; (2) the east region of China has the lowest efficiency of agricultural factor allocation; (3) the breadth of financial market development improves the agricultural factor allocation in all three regions in China, whereas the depth of financial market development only enhances the agricultural factor allocation in the west region of China. Our study presents the very first microlevel evidence on the extent of agricultural factor misallocation in China. Moreover, our results inform policymakers' choice of prioritizing whether the breadth or the depth of the financial market alleviates agricultural factor misallocation.
\end{abstract}

\section{Introduction}

There are vast differences in agricultural productivity across countries (Lagakos and Waugh, 2013 [1]). (The difference in aggregate output per worker between the ninetieth to tenth percentile of the world income distribution is a factor of 22 (Caselli, 2005; Lagakos and Waugh, 2013). The difference in agriculture output per worker is even larger at a factor of 45 . In sharp contrast, the difference in nonagriculture is much smaller at a factor of 4.) Since developing countries generally have most of their population in the agriculture sector, low productivity in the agricultural sector accounts for most low aggregate productivity in developing countries. Consequently, having a deep understanding of agricultural productivity differences is crucial for understanding the income inequality between developed and developing countries. The growth rate of agricultural productivity in China, the world's largest developing country with more than 500 million rural populations, has been lagging behind China's other sectors (Adamopoulos et al., 2020 [2]). Our paper aims to measure the extent of misallocation of agricultural factors in China using nationally representative microlevel data. More importantly, we examine the effect of financial market development on alleviating agricultural factor misallocation, which is a question of paramount interest to academic researchers and policymakers.

To measure the misallocation of factors, we start by constructing a theoretical framework with perfectly competitive factors and product markets. Next, we take our theoretical derivations to the data. We estimate the degree of factor distortion for capital, labor, and land using novel nationally representative household-level survey data from 2010 to 2014. We find that capital and labor prices are negatively distorted, whereas the land price is positively distorted in China. Secondly, we document that agricultural factor allocation efficiency is the lowest in China's east region.

Moreover, we study whether financial market development can lessen the misallocation of agricultural factors. More precisely, we examine the potential differential impacts on misallocation by both the breadth and depth of financial market development. The breadth of financial market development improves agricultural factor allocation efficiency in all three regions of China: the east, the middle, and the west. However, the depth of financial market development only positively impacts the allocation of agricultural factors in China's west region. Our findings provide microlevel evidence on the extent of agricultural misallocation in China and inform the policymakers in deciding 
whether to prioritize the breadth or the depth of financial market development in alleviating agricultural factor misallocation.

Our paper contributes to the literature on the impact of financial markets on resource misallocation. Moll (2014) [3] finds that financial friction is a crucial driver of resource misallocation in emerging markets. Buera et al. (2011) [4] theoretically show that financial market friction distorts capital allocation across firms. Wang and Yuan (2014) [5] report that capital misallocation leads to losses in total factor productivity (TFP). We contribute to this literature by examining the depth and breadth of financial market development in alleviating agricultural factor misallocation using microlevel evidence from China.

We also contribute to the strand of literature that studies the causes of low agricultural productivity in China. Zhu et al. (2011) [6] find that financial friction affects the capital and labor allocation efficiency in China using panel data on rural households from 2003 to 2007. Chen (2012) [7] documents severe misallocation of both capital and labor in China using industry-level panel data from 2004 to 2010, which is supported by Cheng (2016) [8] using province-level panel data from 2000 to 2012. Tu (2017) [9] finds that social capital has a limited impact on China's agricultural productivity using province-level panel data from 1978 to 2014 . We contribute to this strand of literature in three significant ways: (1) instead of focusing on a subset of agricultural industries, we examine all agricultural industries to have a broader picture of agricultural factor misallocation; (2) instead of province-level panel data, our nationally representative household-level microdata allows us to control for granular differences across rural households over time; (3) we provide the very first microlevel evidence on the differential impacts of the breadth and depth of rural financial market development on agricultural factor misallocation.

The rest of the paper is organized as follows. Section 2 discusses our sample selection and summary statistics. Section 3 presents empirical results and discussion. Section 4 concludes by discussing how policymakers can make use of our findings.

\section{Data and Summary Statistic}

We use data from the China Family Panel Studies (CFPS) from 2010 to 2014, a nationally representative and longitudinal survey of Chinese communities, families, and individuals starting in 2010. (The survey has been conducted by the Institute of Social Science Survey (ISSS) of Peking University in China and funded by the Chinese government. Interviews of individuals are all conducted using computerassisted personal interviewing (CAPI) technology, provided by the Survey Research Center (SRC) at the University of Michigan. The CAPI and its associated survey-management system enables the researchers to design a fairly complex interview schedule tailored to each member of the household and reduces measurement error while at the same time allowing the management team at the ISSS to closely monitor the quality of the interviews in the field. The CFPS provides one of the most comprehensive and high-quality survey data on Chinese households to academic researchers)
In the 2010 baseline survey, the CFPS conducted interviews with around 15,000 households and 30,000 individuals. The CFPS respondents are tracked through follow-up surveys. (Our sample ends in 2014 since the 2016 survey data does not include information on households' land usage) Moreover, the survey covers households from 25 provinces in China.

Since our paper focuses on agricultural factor misallocation, we only keep rural households in the dataset. Furthermore, we exclude households that do not have the information to construct our main variables. Following Zhou and Zhou (2011) [10], we create three dummy variables indicating each of the three regions in China, the east, the middle, and the west, to capture the vast differences in economic levels across provinces. (The East region consists of Beijing, Fujian, Guangdong, Hainan, Hebei, Jiangsu, Shandong, Shanghai, Tianjin, Zhejiang, and Liaoning provinces. The middle region includes Anhui, Henan, Hubei, Hunan, Jiangxi, Shanxi, Heilongjiang, and Jilin provinces. The west region includes Gansu, Guangxi, Guizhou, Inner Mongolia, Ningxia, Qinghai, Shanxi, Sichuan, Tibet, Xinjiang, Yunnan, and Chongqing) In the end, our sample includes 9,631 households from 2010 to 2014 .

Table 1 presents the definitions of our main variables and the summary statistics of household-level total agricultural output, capital, land, and labor inputs from 2010 to 2014. (To remove the effect of price inflation from the data, all of our variables are deflated using the 2010 price) The average value of household agricultural output rises 11,363 (RMB) in 2010 to $16,585(\mathrm{RMB})$ in 2014 . There is a more substantial increase in capital input from 4,295 (RMB) in 2010 to 10,491 (RMB) in 2014. The land input increases from 11.13 (mu) (mu is a unit of farmland size in China's own system of weights and measures. $1 \mathrm{mu}$ is equal to 0.16 acre) in 2010 to 12.62 (mu) in 2012 and then declines to 8.83 (mu) in 2014. Similar to the trend in average land input, the average labor input increases from $24,320(\mathrm{RMB})$ in 2010 to 50,194 (RMB) in 2012 and then drops to 33,284 (RMB) in 2014. (Following Yang et al. (2016), we use the wage for migrant workers as the price for the labor input. The wages for migrant workers are obtained in the National Report on Migrant Worker Monitoring and Survey. The wages for migrant workers are relatively stable over and exhibit substantial variations from the east (more developed) to the west (less developed) region of China) Lastly, Table 2 presents the annual value of aggregate agriculture output for each of China's three regions, ranging from 2008 to 2017. The east region has the highest level of aggregate agriculture output, whereas the west region has the lowest level.

\section{Theoretical Framework}

3.1. Model Setup. Following Hsieh and Klenow (2009) [11], Zhu et al. (2011) [6], and Chen (2012) [7], a representative farmer $i$ is assumed to produce a single final agricultural product $Y_{i}$ using inputs of capital $(K)$, labor $(L)$, and farmland $(Z)$ in a perfectly competitive product market. As in Chen (2012) [7], the production function of a representative farmer $i$ is Cobb-Douglas and with a constant return to scale: $Y_{i}=A_{i}$ $K_{i}^{\alpha} L_{i}^{\beta} Z_{i}^{\gamma}(\alpha+\beta+\gamma=1)$, where $Y_{i}$ denotes the real output of farmer $i ; A_{i}, K_{i}, L_{i}, Z_{i}, K_{i}, L_{i}, Z_{i}$ are the total factor productivity 
TABLE 1: Variable definitions and summary statistics.

\begin{tabular}{|c|c|c|c|c|c|}
\hline \multicolumn{2}{|r|}{ Variable } & \multicolumn{4}{|c|}{ Description } \\
\hline$Y$ & Income from agriculture (RMB) & \multicolumn{4}{|c|}{ The total value of agricultural product produced by the household } \\
\hline$K$ & Capital input (RMB) & \multicolumn{4}{|c|}{ The value of capital used in agriculture } \\
\hline$L$ & Labor input (days $*$ wage) & \multicolumn{4}{|c|}{ The number of days households spend on agricultural production $*$ daily wage } \\
\hline$Z$ & Land $(\mathrm{mu})$ & \multicolumn{4}{|c|}{ The area of land used by the household } \\
\hline$P$ & Price of agricultural product (RMB) & \multicolumn{4}{|c|}{ China’s annual national agricultural product wholesale price } \\
\hline$r$ & Interest rate (capital price, \%) & \multicolumn{4}{|c|}{$\begin{array}{l}\text { Interest rate on bank loans (Since China Family Panel Studies (CFPS) survey } \\
\text { households across China every year from March to July, we use the interest rates at } \\
\text { the end of July in each year) }\end{array}$} \\
\hline$w$ & Wage (RMB) & \multirow{2}{*}{\multicolumn{4}{|c|}{$\begin{array}{l}\text { The median value of the daily wage rate agricultural workers within each region } \\
\text { The median value of land transfer price in each region }\end{array}$}} \\
\hline$\xi$ & Land price (Yuan) & & & & \\
\hline Year & Statistics & Agricultural income (RMB) & Capital (RMB) & Land $(\mathrm{mu})$ & Labor (RMB) \\
\hline \multirow{2}{*}{2010} & Mean & 11363.38 & 4296.68 & 11.13 & 24320.38 \\
\hline & SD & 17673.00 & 13334.78 & 31.90 & 14645.03 \\
\hline \multirow{2}{*}{2012} & Mean & 12301.78 & 6123.87 & 12.62 & 50194.12 \\
\hline & SD & 25013.82 & 15757.77 & 41.68 & 16370.23 \\
\hline \multirow{2}{*}{2014} & Mean & 16585.86 & 10491.21 & 8.83 & 33284.22 \\
\hline & SD & 33420.55 & 26149.58 & 22.84 & 14196.12 \\
\hline
\end{tabular}

Notes: we obtain the price of agricultural product from "China's Agricultural Information Network (http://pfsc.agri.cn/) and the benchmark interest rate for loans from the People's Bank of China (http://http://www.pbc.gov.cn/rmyh/index.html). The other variables are calculated from the China Family Panel Studies (CFPS). The summary statistics are calculated from CFPS. "SD" stands for standard deviations.

TAble 2: Gross Output of Agriculture by Region-Year Unit (100 million RMB).

\begin{tabular}{cccc}
\hline Year & East & Midland & West \\
\hline 2017 & 41009.02 & 35642.20 & 32680.46 \\
2016 & 41917.30 & 37402.50 & 31654.20 \\
2015 & 41879.40 & 35698.60 & 29478.20 \\
2014 & 40172.20 & 34445.20 & 27608.70 \\
2013 & 38459.40 & 32740.68 & 25795.19 \\
2012 & 35655.23 & 30201.41 & 23596.41 \\
2011 & 32856.54 & 27352.90 & 21094.51 \\
2010 & 28352.50 & 23314.12 & 17653.14 \\
2009 & 24961.64 & 20261.96 & 15137.38 \\
2008 & 23746.16 & 19395.68 & 14860.33 \\
\hline
\end{tabular}

Note. Calculated from the data of the National Bureau of Statistics (http:// data.stats.gov.cn/index.htm).

(TFP), capital, labor, and farmland inputs of farmer $i$, respectively. Since China's agricultural land can be transferred within the agricultural sector (but not to the nonagricultural sector), we assume that the representative farmer can choose the amount of land $Z_{\mathrm{i}}$ and the total amount of land is fixed at $\bar{Z}$ with $\sum_{i=1}^{n} Z_{i}=\bar{Z}$ with $N$ being the total number of farmers. We also allow the elasticities of capital $(\alpha)$, labor $(\beta)$, and farmland $(\gamma)$ to be different across three regions of China: the east, the middle, and the west.

3.2. Measurement of Factor Misallocations. Following Chari et al. (2010) [12] and Aoki (2012) [13], factor-specific distortions are modeled in the form of linear taxes on each factor input. Farmers are price-takers in all three factor markets and pay linear taxes on all three factors. More precisely, the price of capital is given to farmers as $r$, price of labor (wage) as $w$, and land price $\xi$. Under factor price distortions, the actual costs of capital, labor, and land to farmers are given by $\left(1+\tau_{K}\right) r,\left(1-\tau_{L}\right) w$, and $\left(1+\tau_{Z}\right) \xi$, where $\tau_{K}, \tau_{L}$, and $\tau_{Z}$ denote the capital, labor, and land price distortions (i.e., the linear taxes on the factor prices). We solve the following profit maximization problem with a constraint on the total amount of farmland:

$$
\begin{aligned}
\quad \max \pi_{i} & =P A_{i} K_{i}^{\alpha} L_{i}^{\beta} Z_{i}^{\gamma}-\left(1+\tau_{K_{i}}\right) r K_{i}-\left(1-\tau_{L_{i}}\right) w L_{i}-\left(1+\tau_{Z_{i}}\right) \xi Z_{i} \\
\text { s.t. } \sum_{i=1}^{n} Z_{i} & =\bar{Z},
\end{aligned}
$$

where $P$ is the price of the agricultural product. (1) can be reformulated as

$$
\max \pi_{i}=P A_{i} K_{i}^{\alpha} L_{i}^{\beta} Z_{i}^{\gamma}-\left(1+\tau_{K_{i}}\right) r K_{i}-\left(1-\tau_{L_{i}}\right) w L_{i}-\left(1+\tau_{Z_{i}}\right) \xi Z_{i}+\lambda\left(\bar{Z}-\sum_{i=1}^{n} Z_{i}\right)
$$


where $\lambda$ is the Lagrange multiplier. We take the first-order derivative of (2) with respect to capital $\left(K_{\mathrm{i}}\right)$, labor $\left(L_{\mathrm{i}}\right)$, and land $\left(Z_{\mathrm{i}}\right)$, and $\lambda$, respectively, and set each of the derivatives to zero to arrive at

$$
\begin{aligned}
M R P K_{i} & \equiv \frac{\alpha P Y_{i}}{K_{i}}=r\left(1+\tau_{K_{i}}\right), \\
M R P L_{i} & \equiv \frac{\beta P Y_{i}}{L_{i}}=w\left(1-\tau_{L_{i}}\right), \\
M R P Z_{i} & \equiv \frac{\gamma P Y_{i}}{Z_{i}}=\xi\left(1+\tau_{Z_{i}}\right)+\lambda, \\
\sum_{i=1}^{n} Z_{i} & =\bar{Z},
\end{aligned}
$$

where $Y$ denotes the total output of the agricultural sector, which simply sums up the output by each of the $N$ individual farmers. Combining with equation (5) and letting $1+\mu_{Z}=$ $\sum_{i=1}^{n}\left(1+\tau_{Z_{i}}\right)\left(Z_{i} / \bar{Z}\right)\left(\mu_{Z}\right.$ can be seen as the average degree of distortion of the land market across $N$ farmers), we can formulate total output $Y$ as

$$
Y=\sum_{i=1}^{n} Y_{i}=\frac{\left[\xi\left(1+\mu_{Z}\right)+\lambda\right] \bar{Z}}{\gamma P},
$$

which further characterizes the relation between total output and the total amount of land $\bar{Z}$. Additionally, we can derive the shadow price of land using (7) as

$$
\lambda=\frac{\gamma P Y}{\bar{Z}}-\xi\left(1+\mu_{Z}\right) .
$$

As seen from (8), the shadow price of land $\lambda$ measures the difference between the average product of the land and the average distorted price of land. Moreover, we can derive the optimal amount of capital $\left(K_{\mathrm{i}}\right)$ and labor $\left(L_{\mathrm{i}}\right)$ given the amount of land $\left(Z_{\mathrm{i}}\right)$ as

$$
\begin{gathered}
K_{i}=\frac{\alpha\left[\xi\left(1+\tau_{Z_{i}}\right)+\lambda\right]}{\gamma r\left(1+\tau_{K_{i}}\right)} Z_{i}, \\
L_{i}=\frac{\beta\left[\xi\left(1+\tau_{Z_{i}}\right)+\lambda\right]}{\gamma w\left(1-\tau_{L_{i}}\right)} Z_{i} .
\end{gathered}
$$

Letting $\left(1 /\left(1+\mu_{K Z}\right)\right)=\sum_{i=1}^{n}\left(\left(1+\tau_{Z_{i}}\right) /\left(1+\tau_{K_{i}}\right)\right)\left(Z_{i} / \bar{Z}\right)$ and $\left(1 /\left(1+\mu_{L Z}\right)\right) \equiv \sum_{i=1}^{n}\left(\left(1+\tau_{Z_{i}}\right) /\left(1-\tau_{L_{i}}\right)\right)\left(Z_{i} / Z\right)$, where $\mu_{K Z}\left(\mu_{L Z}\right)$ is the average distortion of capital (labor) relative to land, we can get the total amount of capital and labor used as

$$
\begin{aligned}
& K=\sum_{i=1}^{n} K_{i}=\frac{\alpha}{\gamma r}\left[\frac{\zeta}{1+\mu_{K Z}}+\sum_{i=1}^{n} \frac{\lambda}{1+\tau_{K_{i}}} \frac{Z_{i}}{\bar{Z}}\right] \bar{Z}, \\
& L=\sum_{i=1}^{n} L_{i}=\frac{\beta}{\gamma w}\left[\frac{\zeta}{1+\mu_{L Z}}+\sum_{i=1}^{n} \frac{\lambda}{1-\tau_{L_{i}}} \frac{Z_{i}}{\bar{Z}}\right] \bar{Z} .
\end{aligned}
$$

Plugging equations (10) and (11) back into the production function of the agricultural sector, $Y_{i}=A_{i} K_{i}^{\alpha} L_{i}^{\beta} Z_{i}^{\gamma}$, we can rewrite the total output $Y$ as

$$
Y=\left[A\left(\frac{\alpha}{\gamma r}\right)^{\alpha}\left(\frac{\beta}{\gamma w}\right)^{\beta}\right]\left[\frac{\zeta}{1+\mu_{K Z}}+\sum_{i=1}^{n} \frac{\lambda}{1+\tau_{K_{i}}} \frac{Z_{i}}{\bar{Z}}\right]^{\alpha}\left[\frac{\zeta}{1+\mu_{L Z}}+\sum_{i=1}^{n} \frac{\lambda}{1-\tau_{L_{i}}} \frac{Z_{i}}{\bar{Z}}\right]^{\beta} \bar{Z}
$$

Combining equations (12) and (7), we derive the expression total factor productivity $\mathrm{A}$ as

$$
A=\frac{1}{P \gamma^{\gamma}}\left(\frac{r}{\alpha}\right)^{\alpha}\left(\frac{w}{\beta}\right)^{\beta} \frac{\zeta\left(1+\mu_{Z}\right)+\lambda}{\left[\left(\zeta /\left(1+\mu_{K Z}\right)\right)+\sum_{i=1}^{n}\left(\lambda /\left(1+\tau_{K_{i}}\right)\right)\left(Z_{i} / \bar{Z}\right)\right]^{\alpha}\left[\left(\zeta /\left(1+\mu_{L Z}\right)\right)+\sum_{i=1}^{n}\left(\lambda /\left(1-\tau_{L_{i}}\right)\right)\left(Z_{i} / \bar{Z}\right)\right]^{\beta}}
$$

The benchmark total factor productivity $\bar{A}$ when there is no factor misallocation is given by

$$
\bar{A}=\frac{1}{P \gamma^{\gamma}}\left(\frac{r}{\alpha}\right)^{\alpha}\left(\frac{w}{\beta}\right)^{\beta}(\zeta+\lambda)^{1-\alpha-\beta} .
$$

The connection between total factor productivity A and $\bar{A}$ can be summarized as

$$
A=\mathrm{DI} * \bar{A},
$$

where DI (distortion index) can be seen as an index of total distortion for each region and is given by

$$
\mathrm{DI}=\frac{\left[\zeta\left(1+\mu_{Z}\right)+\lambda\right](\zeta+\lambda)^{\alpha+\beta-1}}{\left[\left(\zeta /\left(1+\mu_{K Z}\right)\right)+\sum_{i=1}^{n}\left(\lambda /\left(1+\tau_{K_{i}}\right)\right)\left(Z_{i} / \bar{Z}\right)\right]^{\alpha}\left[\left(\zeta /\left(1+\mu_{L Z}\right)\right)+\sum_{i=1}^{n}\left(\lambda /\left(1-\tau_{L_{i}}\right)\right)\left(Z_{i} / \bar{Z}\right)\right]^{\beta}} .
$$


Similarly, for each farmer $i$, the distortion index $D I_{\mathrm{i}}$ can

be written as

$$
\mathrm{DI}_{i}=\frac{(\zeta+\lambda)^{\alpha+\beta}}{\left[\left(\zeta\left(1+\tau_{Z_{i}}\right)+\lambda\right) /\left(1+\tau_{K_{i}}\right)\right]^{\alpha}\left[\left(\zeta\left(1+\tau_{Z_{i}}\right)+\lambda\right) /\left(1-\tau_{L_{i}}\right)\right]^{\beta}}
$$

\section{Empirical Analysis}

4.1. Measuring Factor Elasticities. Based on our theoretical framework, the distortion index (DI) calculation requires the actual values of factor elasticities: $\alpha, \beta$ and $\gamma$. We estimate the following equation to measure factor elasticities for capital, labor, and land:

$$
\begin{aligned}
\ln Y_{i t}= & \alpha \ln K_{i t}+\beta \ln L_{i t}+\gamma \ln Z_{i t} \\
& + \text { time dummies }+u_{i}+\varepsilon_{i t},
\end{aligned}
$$

where $Y_{i t}, K_{i t}, L_{i t}$, and $Z_{i t}$ are the income from agriculture, capital input, and labor input for farmer $i$ in year $t$; time $d u$ mmies are a set of dummies for calendar years; $u_{\mathrm{i}}$ is farmer fixed effect. Our standard errors are clustered by rural households to account for potential transitory shocks that are correlated across time for a specific rural household. Following Mundlak (2001) [14], Zhu et al. (2011) [6], and Chen (2012) [7], we estimate the equation with a fixed-effect model.

Following Li et al. (2010) [15] and Zhu et al. (2011) [6], we standardize factor elasticities for each region by letting $\alpha+\beta+\gamma=1$. As from Table 3, the elasticity of capital is over two-thirds for all three regions in China and is far higher than the elasticities for both labor and land. Moreover, the elasticity of land is significantly higher than the elasticity of labor. Since the elasticity of a factor represents the share of output by that factor, the average share of output by capital is $71.33 \%$, by labor $8 \%$, and by land $20.67 \%$ across three regions in China. Our estimation results are consistent with the welldocumented fact that China's agricultural sector has a limited supply of both capital and land but has abundant labor supply (Zhu et al., 2011 [6]).

4.2. Shadow Price of Land. Turning back to equation (6) listed below, we can calculate the shadow price of land by taking the difference between the average product of the land and the average distorted land price.

$$
\lambda=\frac{\gamma P Y}{\bar{Z}}-\xi\left(1+\mu_{Z}\right)
$$

Since our production function is Cobb-Douglas, the marginal output of land is given by

$$
\frac{\partial Y_{i}}{\partial Z_{i}}=\frac{Y_{i}}{Z_{i}} \frac{\partial \ln Y_{i}}{\partial \ln Z_{i}}=\gamma \frac{Y_{i}}{Z_{i}}
$$

Based on (16), the average product of land for each region-year can be calculated as

$$
\frac{1}{n} \sum_{i=1}^{n} \frac{\partial Y_{i}}{\partial Z_{i}}=\frac{\gamma}{n} \sum_{i=1}^{n} \frac{Y_{i}}{Z_{i}}
$$

We present the average marginal output of land, the actual land price, and the calculated shadow price of land in Table 3. We find that land's marginal output is highest in China's east region, followed by the west region, and lowest in the middle region. The land price is decreasing from the west, the east, and the middle. Lastly, land shadow price is highest in the east region, followed by the west region, and lowest in the middle region. Since the shadow price is the increase in agricultural output, if the land constraint is relaxed by 1 unit, the east region of China will have the most significant increase in agricultural output if it had more land. Besides, the shadow price of land in the year 2012 is negative for all regions. A negative shadow price of land implies that agricultural output would decline if there was more land used in agriculture in that year (Cheng et al. 2016 [8]).

Moreover, we document that the shadow price of land is positive for most region-years, which implies that the marginal output of land is higher than the actual price of land. The suppressed price of land in China potentially leads to inefficient land allocation (i.e., from unproductive to productive farmers).

4.3. Measuring the Degree of Distortion for Each Factor. Combining both factor elasticities and land shadow price, we can calculate the degree of distortion for capital, land, and labor by each region and year, respectively. As seen from Table 4, the distortion of capital is negative across all regionyears, which potentially results from heavy government regulations on interest rates in China's rural financial markets. Moreover, we take the absolute value of the factor price distortion as a measure of the degree of factor distortion. Besides, we see from Table 4 that the degree of capital distortion has been worsened in both the east and west regions of China from 2010 to 2014. In contrast, the middle region of China has a modest improvement in capital distortion from -0.9 in 2010 to -0.84 in 2014 . Turning to labor distortion in Table 4, the price distortion of labor does not vary significantly within each of the three regions across the years. However, the middle region of China has the highest average price distortions from 2010 to 2014. Lastly, the price distortion of land has deteriorated in the east and the west regions of China. In contrast, the middle region of China has reduced land price distortion from 2010 to 2014.

We calculated an aggregate distortion index (DI) that summarizes the price distortions of three factor inputs. Following Chen (2012) [7], we use the level of price distortion of land as a benchmark standardized to one. Hence, 
TABle 3: Factor elasticities and shadow price of land $(\lambda)$ in China.

\begin{tabular}{llccc}
\hline & & East & Middle & West \\
\hline Capital & & 0.75 & 0.68 & 0.71 \\
Labor & & 0.08 & 0.04 & 0.12 \\
Land & 0.17 & 0.28 & 0.17 \\
\hline Region & Year & Marginal output of land (RMB/mu/year) & Price of land (RMB/mu/year) & Shadow price of land $(\lambda)(\mathrm{RMB} / \mathrm{mu} /$ year) \\
\hline \multirow{6}{*}{ East } & 2010 & 872.76 & 232.16 & 640.60 \\
& 2012 & 132.26 & 254.29 & -122.03 \\
& 2014 & 2064.95 & 260.95 & 1804.00 \\
Midland & 2010 & 541.31 & 78.13 & 463.18 \\
& 2012 & 170.76 & 200.00 & -29.24 \\
\multirow{2}{*}{ West } & 2014 & 617.33 & 368.19 & 249.14 \\
& 2012 & 1028.31 & 277.06 & 751.25 \\
\end{tabular}

TABle 4: Degree of distortion of factors by region-year (2010-2014).

\begin{tabular}{|c|c|c|c|c|c|}
\hline & Variable & Year & East & Midland & West \\
\hline \multirow{7}{*}{ Capital } & \multirow{3}{*}{ Distortion (mean) } & 2010 & -0.68 & -0.90 & -0.27 \\
\hline & & 2012 & -0.78 & -0.83 & -0.65 \\
\hline & & 2014 & -0.84 & -0.84 & -0.85 \\
\hline & \multirow{4}{*}{ Distortion (std. deviation) } & 2010 & 122.11 & 111.51 & 135.10 \\
\hline & & 2012 & 78.27 & 70.67 & 85.03 \\
\hline & & 2014 & 67.97 & 74.35 & 88.24 \\
\hline & & 2010 & 0.96 & 0.98 & 0.86 \\
\hline \multirow{5}{*}{ Labor } & \multirow[t]{3}{*}{ Distortion (mean) } & 2012 & 0.97 & 0.99 & 0.93 \\
\hline & & 2014 & 0.96 & 0.98 & 0.97 \\
\hline & & 2010 & 116.25 & 58.59 & 116.58 \\
\hline & \multirow[t]{3}{*}{ Distortion (std. deviation) } & 2012 & 68.64 & 9.79 & 72.35 \\
\hline & & 2014 & 59.81 & 47.66 & 32.42 \\
\hline \multirow{6}{*}{ Land } & & 2010 & 197.30 & 563.26 & 102.34 \\
\hline & \multirow[t]{2}{*}{ Distortion (mean) } & 2012 & 205.84 & 252.64 & 122.88 \\
\hline & & 2014 & 268.99 & 279.94 & 245.61 \\
\hline & \multirow{3}{*}{ Distortion (std. deviation) } & 2010 & 547.32 & 684.81 & 409.52 \\
\hline & & 2012 & 542.53 & 508.32 & 528.49 \\
\hline & & 2014 & 692.54 & 583.17 & 984.95 \\
\hline
\end{tabular}

we can calculate the aggregate distortion index $(D I)$ as follows:

$$
\begin{aligned}
\mathrm{DI} & =\frac{[\zeta(1+1)+\lambda](\zeta+\lambda)^{\alpha+\beta-1}}{\left[\left(\zeta /\left(1+\mu_{K Z}\right)\right)+\sum_{i=1}^{n}\left(\lambda /\left(1+\tau_{K_{i}}\right)\right)\left(Z_{i} / \bar{Z}\right)\right]^{\alpha}\left[\left(\zeta /\left(1+\mu_{L Z}\right)\right)+\sum_{i=1}^{n}\left(\lambda /\left(1-\tau_{L_{i}}\right)\right)\left(Z_{i} / \bar{Z}\right)\right]^{\beta}}, \\
\mathrm{DI}_{i} & =\frac{(\zeta+\lambda)^{\alpha+\beta}}{\left[(\zeta(1+1)+\lambda) /\left(1+\tau_{K_{i}}\right)\right]^{\alpha}\left[(\zeta(1+1)+\lambda) /\left(1-\tau_{L_{i}}\right)\right]^{\beta}} .
\end{aligned}
$$

We present the aggregate distortion index for each region-year in Table 5. The level of aggregate distortion declines from 2010 to 2012. However, it increases from 2012 to 2014 for both the east and middle regions of China. The west region has experienced a monotonically decreasing trend of aggregate distortion from 2010 to 2014 .

\subsection{Impact of Financial Market Development on Agricultural Factor Misallocation}

4.4.1. Model Specification. To examine the impact of financial market development on agricultural factor misallocation in China, we specify our regression model as follows: 
TABLE 5: Total distortions of factor prices by region from 2010 to 2014.

\begin{tabular}{|c|c|c|c|c|c|}
\hline & Variable & Year & East & Middle & West \\
\hline \multirow{6}{*}{ Total distortions } & \multirow{4}{*}{ Distortions level (mean) } & 2010 & 1.23 & 0.83 & 2.30 \\
\hline & & 2012 & 0.42 & 0.48 & 0.67 \\
\hline & & 2014 & 1.24 & 0.59 & 0.56 \\
\hline & & 2010 & 25.19 & 13.61 & 25.56 \\
\hline & \multirow{2}{*}{$\begin{array}{c}\text { Twisted divergence } \\
\text { (SD) }\end{array}$} & 2012 & 8.47 & 5.83 & 10.14 \\
\hline & & 2014 & 18.06 & 8.12 & 17.16 \\
\hline
\end{tabular}

$$
\begin{aligned}
{\text { In } \text { distort }_{\text {dit }}=} & \beta_{0}+\beta_{1} \text { nonratio }_{v t}+\beta_{2} \text { creditratio }_{v t} \\
& +\beta_{3} \text { nonhousing_debts } \\
& + \text { controls }+g_{\mathrm{di}}+\rho_{\mathrm{dit}}
\end{aligned}
$$

where $\ln$ distort $_{\text {dit }}$ is the degree of distortion for factor $d(d$ can be either capital, land, labor, and distortion index (DI) (Hence, $\ln$ distort $_{\mathrm{dit}}$ can be either $\ln 1+\tau$ Kit, $\ln 1-\tau$ Lit, $\ln 1+\tau$ Zit, or $\operatorname{lnD}$ Iit)), farmer $i$, and year $t$. nonratio ${ }_{v t}$ stands for nonagricultural employment opportunities in village $v$ and year $t$, which is the proportion of nonagricultural employment labor force. (Nonagricultural employment includes people that go out to work, work locally, and work in the nonagricultural industries) creditratio $_{v t}$ proxies for the breadth of rural financial market development in village $v$ and year $t$, which is calculated as the proportion of farmers who receive loans in the local village. nonhousing_debts proxies for the depth of rural financial market development in village $v$ and year $t$, which is calculated as the financial liabilities of nonresidential loans of farmers (RMB). controls are a set of control variables including family size; whether the farmer receives government subsidies; the age, education, and gender of household head; whether the household head is healthy. $g_{d i}$ is the agricultural factor-farmer fixed effect to account for fixed heterogeneities in rural households' efficiency in using the factors. All standard errors are clustered at the household level.

4.4.2. Empirical Results and Discussion. We summarize in Table 6 the impact of financial market development on distortions of agricultural factors.

The breadth of financial market development has improved the allocation of capital in the west and the land allocation in the east and the west regions of China. However, labor allocation in all three regions is worsened by the breadth of financial market development. Combining the impact of financial market development breadth on three factors, we see that the breadth of financial market has lessened the aggregate agricultural factor distortion (distortion index (DI)) for all three regions in China. Our result provides microlevel evidence on the significant role played by the breadth of the financial market in enhancing agricultural factor productivity in China. We use the percentage of farmers who receive loans in the village as a proxy for the breadth of the financial market. Our results underscore the value of lending to households that did not have access to the rural financial market. Policymakers shall read into our results by encouraging financial institutions to design more innovative lending policies that do not rely solely on collaterals. Currently, most of the lending in rural areas is based on collaterals. Consequently, policymakers in China can provide financial institutions with incentives to collect more soft information from farmers, giving a higher weight in lending decisions.

Turning to the depth of financial market development, it enhances capital allocation in China's west region. However, the financial market's depth worsens land allocation in the west region of China. It has no significant impact on other factor distortions in other regions. In total, the depth of the financial market has improved the total factor distortion level in the west region of China. Our finding points to the positive impact of developing the rural financial market's depth on enhancing agricultural factor productivity in China's west region. We use "households" nonhousing debt as a proxy for the depth of the financial market. Our result is consistent with the underdevelopment of the rural financial market in the west region. Consequently, policies that encourage more lending to creditworthy farmers in the west region can significantly boost agricultural productivity.

\subsection{Discussion on the Impact of Rural-Urban Migration on} Agricultural Factor Misallocation. Although our paper focuses on the impact of financial market development on agricultural factor misallocation, it is of great policy relevance to consider other significant factors shaping agricultural factor misallocation in China. One of the most critical factors is the rural to urban migration in China. An emerging literature has been studying the patterns and determinants of rural to urban migration. For example, $\mathrm{Gu}$ et al. (2020a) [16] employ spatial analysis methods and the eigenvector spatial filtering gravity model to study the spatial pattern and determinants of the Hukou transfer intention network in China. Gu et al. (2020b) [17] document that rural-urban migrants in China with access to a rural homestead are $12 \%$ less likely to transfer their rural Hukou to urban Hukou than those without access to a rural homestead.

Our paper provides estimates of the degree of distortion for capital, land, and labor in China using household-level survey data. Building on our results, future researchers can construct a multiregion spatial model that allows migration across different regions, which can be employed to answer many critical questions. For example, does rural to urban migration increase or decrease the agricultural factor misallocation in China? For regions in China with limited land and capital but abundant labor, labor migration out of those regions might increase agricultural factor allocation efficiency. The answer to this question is also of paramount 


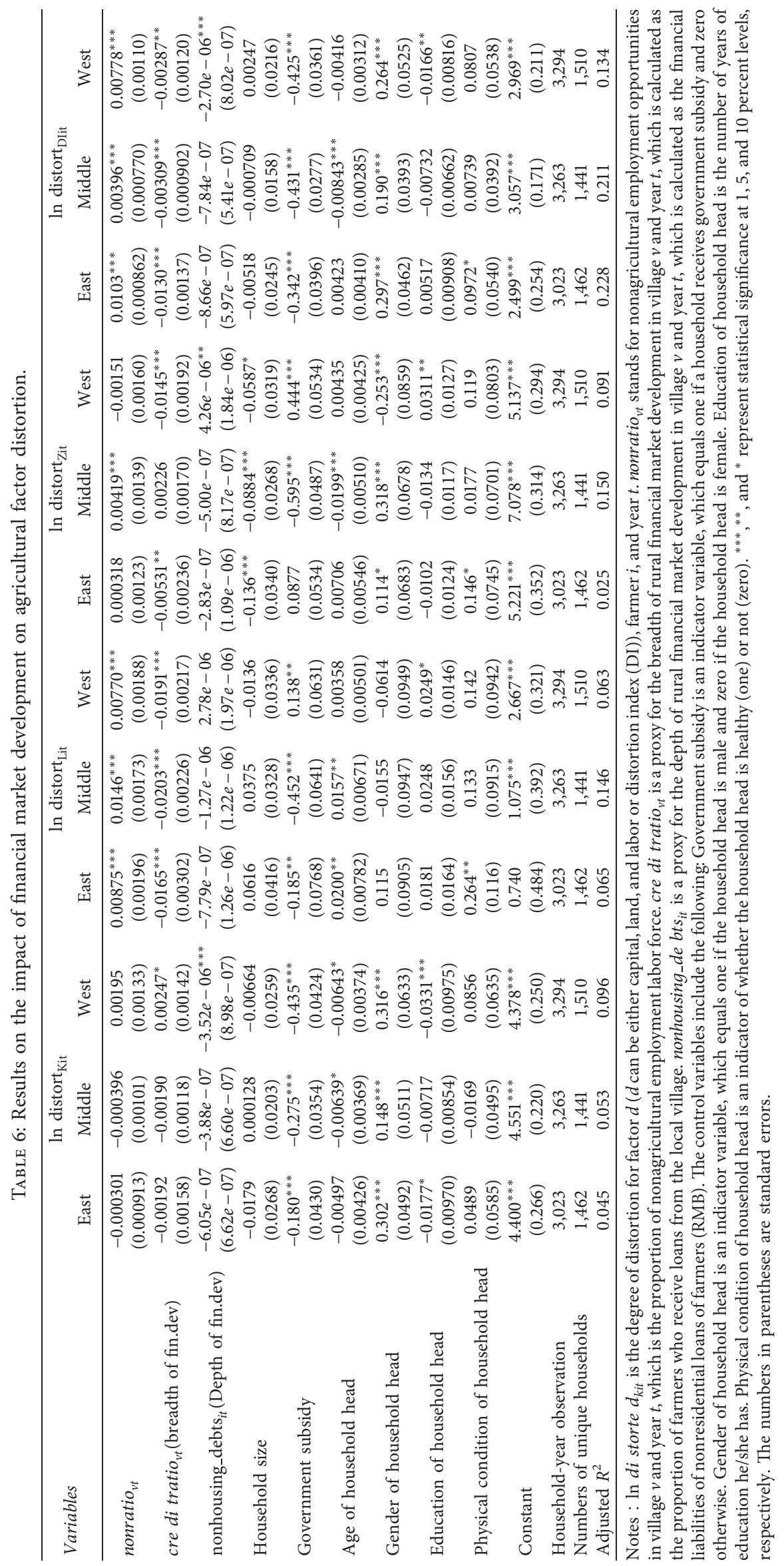


interest to policymakers in China. However, the multiregion spatial model is far beyond our paper's scope, and we strongly encourage future researchers to tackle this valuable research question.

\section{Conclusion and Policy Implications}

Our paper starts with constructing a theoretical framework with perfectly competitive factors and product markets. Our model's mathematical derivations shed light on empirically estimating agricultural factors' misallocation across different regions of China. We employ a nationally representative household survey panel data (CFPS) from 2010 to 2014. Our research not only provides microlevel evidence on the degree of agricultural factor misallocation in China but also examines the impact of the breadth and depth of financial market development on agricultural factor allocation.

Our empirical results show the following: (1) the prices of capital and labor are negatively distorted, whereas the price of land is positively distorted; (2) the efficiency of allocation of agricultural factors is lowest in the east region of China; (3) the breadth of financial market development improves the total allocation of factors in all three regions, whereas the depth of financial market development only has a positive impact on the allocation of factors in the west region of China. In summary, the development of the financial market alleviates the misallocation of agricultural factors in China.

Our findings contribute to the literature on factor misallocation. More specifically, we document significantly different impacts of the depth and breadth of financial market development on agricultural factor misallocation, which furthers our understanding of financial markets' role in alleviating factor misallocation. Moreover, our nationally representative household-level microdata allows us to control for differences across rural households over time, overcoming some of the data difficulties in previous studies that either focus on a narrow set of industries or use province-level data. Policymakers in China and other developing countries can also benefit from our microlevel evidence on the breadth and depth of rural financial market development on agricultural factor misallocation. The main takeaway for policymakers is to focus on strengthening the breadth of financial market development in all three regions of China and the depth of financial development in the west region.

\section{Data Availability}

The data are available and explained in this article; readers can access the data supporting the conclusions of this study.

\section{Conflicts of Interest}

The authors declare that there are no conflicts of interest.

\section{Authors' Contributions}

All authors approved the final version of the manuscript.

\section{Acknowledgments}

The authors extend their gratitude to the Philosophy and Social Science Foundation of Guangdong Province (Grant no. GD19CYJ13), Guangdong Natural Science Foundation (Grant no. 2021A1515011926), and Special Funds for the Cultivation of Guangdong College Students' Scientific and Technological Innovation (Grant no. pdjh2021a0074).

\section{References}

[1] D. Lagakos and M. E. Waugh, "Selection, agriculture, and cross-country productivity differences," American Economic Review, vol. 103, no. 2, pp. 948-980, 2013.

[2] T. Adamopoulos, L. Brandt, J. Leight, and D. Restuccia, "Misallocation, selection and productivity: a quantitative analysis with panel data from China," NBER Working Paper No, vol. 23039, 2020.

[3] B. Moll, "Productivity losses from financial frictions: can selffinancing undo capital misallocation?" American Economic Review, vol. 104, no. 10, pp. 3186-3221, 2014.

[4] F. J. Buera, J. P. Kaboski, and Y. Shin, "Finance and development: a tale of two sectors," American Economic Review, vol. 101, no. 5, pp. 1964-2002, 2011.

[5] L. H. Wang and L. Yuan, "Can capital misallocation cause TFP losses?” Statistical Research, vol. 31, no. 8, pp. 11-18, 2014.

[6] X. Zhu, Q. H. Shi, and Q. E. Ge, "Misallocation and TFP in rural China," Jingji Yanjiu (Economic Research Journal), vol. 46, no. 5, pp. 86-98, 2011.

[7] X. B. Chen, "Resource distribution, total factor productivity and the future of agricultural economic growth," Gaige (Reform), vol. 8, pp. 82-90, 2012.

[8] L. W. Cheng, Y. Xu, and C. Q. Tao, "Loss caused by factor misallocation to the agricultural sector in China: evidence based on a stochastic frontier trans-logarithm production function model," Journal of Management, vol. 29, no. 1, pp. 24-34, 2016.

[9] S. W. Tu, "The changes in the efficiency of agricultural factor allocation in China," Research on Macroeconomics, vol. 12, pp. 148-162, 2017.

[10] W. P. Zhou and S. Zhou, "Analysis of incentive mechanism in the development of new rural financial institutions in China," Macroeconomic, vol. 12, pp. 19-26+48, 2011.

[11] C.-T. Hsieh and P. J. Klenow, "Misallocation and manufacturing TFP in China and India," Quarterly Journal of Economics, vol. 124, no. 4, pp. 1403-1448, 2009.

[12] V. V. Chari and E. R. Kehoe, "Mcgrattan. Business cycle accounting," Econometrica, vol. 75, no. 3, pp. 781-836, 2010.

[13] S. Aoki, "A simple accounting framework for the effect of resource misallocation on aggregate productivity," Journal of the Japanese and International Economies, vol. 26, no. 4, pp. 473-494, 2012.

[14] Y. Mundlak, "Production and supply," Handbook of Agricultural Economics, vol. 85, 2001.

[15] C. G. Li, Z. C. Feng, and L. X. Fan, "Is the small-sized rural household more efficient?" The Empirical Evidence from Hubei Province, vol. 9, no. 01, pp. 95-124, 2010.

[16] H. Gu, Z. Liu, and T. Shen, "Spatial pattern and determinants of migrant workers' interprovincial hukou transfer intention in China: evidence from a National Migrant Population Dynamic Monitoring Survey in 2016," Population, Space and Place, vol. 26, no. 2, pp. e2250.1-e2250.16, 2020.

[17] H. Gu, Y. Ling, T. Shen, and L. Yang, "How does rural homestead influence the hukou transfer intention of rural-urban migrants in China?" Habitat International, vol. 105, pp. 1-11, 2020. 